\title{
PERKEMBANGAN MEDIA SOSIAL DAN ONLINE ADVERTISING DAPAT MEMPENGARUHI PENCARIAN KERJA PARA KARYAWAN
}

\author{
Daniel Arie Polim dan Carol Daniel Kadang \\ Program Studi Manajemen Fakultas Ekonomi Universitas Tarumanagara, Jakarta
}

danielarie1112@gmail.com

\begin{abstract}
Abstrak: Penelitian ini bertujuan untuk mengetahui pengaruh media sosial dan online advertising terhadap pencarian kerja karyawan di daerah Jakarta Barat. Desain penelitian yang digunakan adalah kausal dengan menggunakan metode kuantitatif dan kuesioner dalam bentuk google form. Penelitian ini menggunakan software smartPLS dalam mengolah data penelitian. Hasil penelitian yang didapatkan dapat disimpulkan bahwa media sosial dan online advertising memiliki pengaruh yang positif dan signifikan terhadap pencarian karyawan di daerah Jakarta Barat.
\end{abstract}

Kata Kunci : media sosial, online advertising, pencarian kerja.

Abstract: This study aims to determine the effect of social media and online advertising on employee job search in the West Jakarta area. The research design used is causal by using quantitative methods and questionnaires in the form of google form. This research uses smartPLS software in processing research data. The results obtained can be concluded that social media and online advertising have a positive and significant influence on employee search in the West Jakarta area.

Keywords: media social, online advertising, job search.

\section{PENDAHULUAN}

Perkembangan media sosial dan online advertising pada era ini sangatlah maju sehingga dalam pencarian informasi sangatlah mudah. Penggunaan internet sekarang ini telah menjadi kebutuhan sehari-hari yang tidak dapat diabaikan dalam kehidupan bagi masyarakat. Internet dapat digunakan untuk berbagai hal, salah satunya untuk mengakses media sosial (Alvionita dan Mei Ie. 2021). Penelitian ini berjudul tentang perkembang media sosial dan online advertising yang dapat mempengaruhi pencarian kerja karyawan. Perkembangan ini dibuktikan dengan banyaknya platform atau tempat untuk memberikan informasi terkait pekerjaan. Dari media sosial orang - orang ini juga menemukan banyak hal yang berguna dalam kehidupan mereka mulai dari belanja kebutuhan sehari-hari, mencari teman lama yang sudah tidak berinteraksi dalamjangka waktu lama dan masih banyak lagi (Suhartono Chandra dan Richard Andrew, 2018). Dilihat dari perkembangannya media sosial dan online advertising pada saat ini sudah menjadi salah satu cara untuk mencari pekerjaan atau perusahaan sedang menjadi pekerja. Maka dari itu penulis ingin membuktikan dengan melakukan penelitian ini untuk hasil yang baik. Pencarian kerja memiliki arti sebagai proses yang mempertemukan antara pekerja dengan pekerjaan yang sesuai. Media sosial dan iklan online ini dapat menjadi sarana untuk mencari pekerja yang sesuai dengan pekerjaannya karena dalam iklan tersebut bisa memberikan kualifikasi dan syarat dalam menerima pekerjaan. Menurut Kotler dan Amstrong 
(2012) mengatakan bahwa iklan yang ada dalam internet memiliki banyak tujuan dan manfaat untuk banyak pihak. Iklan juga didefinisikan sebagai segala bentuk promosi ide, barang atau jasa secara non personal oleh suatu sponsor dari perusahaan. menurut Chaffey (2018) mengungkapkan bahwa Indonesia adalah salah satu dari 10 negara yang menggunakan media sosial terbanyak dan terbesar di Indonesia. Maka dari itu penulis ingin adanya penelitian yang membuktikan bahwa pencarian kerja dengan menggunakan media sosial dan iklan online dapat menjadi sarana yang lebih efektif dari pada harus menggunakan cara yang sudah tertinggal zaman.

\section{KAJIAN TEORI}

Pencarian Kerja. Pencarian kerja didefinisikan sebagai carai seseorang atau pekerja yang mencari pekerjaan yang sesuai dengan kriteria dan minat dari pekerja tersebut. Menurut Plummer, Hiltz\&Llotnick (2011) dimana pada saat ini cara pandang perusahaan dan pada pengusaha dalam perekrutan pekerja individu dan pencarian kerja terhubung dan dapat berinteraksi antara satu dengan yang lain. Menurut Aluri (2019); Holler (2008) menyebutkan ada 4 dimensi yang dapat digunakan dalam pencarian kerja: Fast-Paced (Serba Cepat), Communication-Saturated (Jenuh Komunikasi), Well-Connected (Terhubung dengan baik), Tech-Savvy (Paham akan teknologi).

Media Sosial. Media sosial adalah suatu rangkaian aplikasi atau software yang dapat menghubungkan pelanggan dalam melakukan interaksi, penciptaan bersama, pertukaran informasi secara publik dan pembentukan jaringan komunitas ( Larson dan Watson, 2011). Dalam perkembangan media sosial pada era saat ini banyak sekali kegunaan dan pengembangan yang memudahkan penggunanya. Memudahkan penggunanya dengan media sosial menjadi hal baik bagi media sosial tersebut, dan menurut Purnama (2011:116) media sosial diartikan dimensi nya sebagai: Jangakauan (reach), aksesbilitas (accessibility), penggunaan (usability), Aktualits (immediacy), Tidak Permanen (replacment), Frekuensi (frequency).

Online Advertising. Online advertising diartikan sebagai cara perusahaan untuk memberikan informasi kepada masyarakat akan produk atau jasa yang ada. Iklan online memiliki kelebihan dimana semua iklan tersebut dapat tumbuh secara cepat, menggunakan pengeluaran yang relatif lebih murah dan juga menjangkau semua individu (Kotler dan Amstrong, 1997:80). Berkembangannya iklan online pada era saat ini banyak sekali hal yang dapat dilakukan karena lebih mudah dijangkau dan cepat tersebar. Online advertising memiliki dimensi yang dapat membantu menjelaskan definisi diatas, antara lain adalah : Attention, Interest, Desire, Action.

Kaitan antara Media Sosial dan Pencarian Kerja. Menurut Mellyana, Prima \& Imran (2018) dalam penelitiannya tentang Penggunaan Media Sosial di lingkungan kerja di perguruan tinggi $X Y Z$, bahwa media sosial memiliki pengaruh positif dan signifikan terhadap pencarian kerja. Penelitian tersebut hampir $85 \%$ responden menjawab membutuhkan media sosial untuk mencari kerja pada era ini atau juga mereka membutuhkan media sosial untuk mencari informarsi agak lebih mudah di dapatkan. Lalu menurut Ahmad Fauzan (2017) dalam artikelnya yang berjudul Perilaku di Media sosial, Pengaruhi karir dalam artikelnya menuliskan saat ini media sosial sangat berpengaruh positif dan signifikan terhadap pencarian kerja. Karena pada saat ini media sosial sebagai dasar perusahaan dalam mengembangkan dan mencari karyawan untuk bekerja didalam perusahaan. Apalagi pada saat ini menurut nya sebanyak $45 \%$ perusahaan yang ada dijakarta melihat media sosial para calon pekerja sebagai 
dasar pertimbangan untuk diterima kerja karena sebagai cara mengidentifikasi calon pekerja apakah media sosial mereka digunakan dengan baik atau tidak.

Kaitan antara Online Advertising dan Pencarian Kerja. Menurut Maryanah, Aldhila, Astrid (2018) tentang penelitiannya berjudul Sistem Informasi lowongan kerja berbasis Web, yang dimana Online Advertising sangat berpengaruh positif dan signifikan terhadap pencarian kerja. Dikarenakan web atau iklan yang ada pada suatu laman tersebut memberikan informasi bagi calon pekerja dengan lowongan pekerjaan yang tersedia, serta hasil lamaran yang diberikan oleh perusahaan bagi calon pekerja tersebut. Lalu bagi perusahaan memberikan informasi dalam iklan tersebut agar para calon pekerja mendaftar sesuai kualifikasi yang dibutuhkan oleh perusahaan Lalu menurut Anggita Dwinda (2020) dalam artikel yang dituliskan berjudul Manfaat pasang Iklan Lowongan kerja di Job Portal membuktikan bahwa online advertising berpengaruh positif dan signifikan bagi pencarian kerja dikarenakan pada saat ini hampir semua perusahaan di Indonesia memiliki cara dan proses rekrutmen melalui online dikarena menurut nya banyak hal yang lebih munguntungkan perusahaan. Seperti online advertising dapat menjangkau lebih banyak kandidat yang dimana lebih fleksibel dan tak terbatas. Lalu oromatisasi proses nya yang dapat meningkatkan pengalam positif bagi kandidat atau calon pekerja dan yang pasti biaya yang digunakan relatif lebih murah dari offline advertising.

Berdasarkan kaitan antar variabel yang ditunjukana dari hasil penelitian yang terdahulu yang dijelaskan diatas, berikut merupakan model yang digunakan dapat penelitian ini:

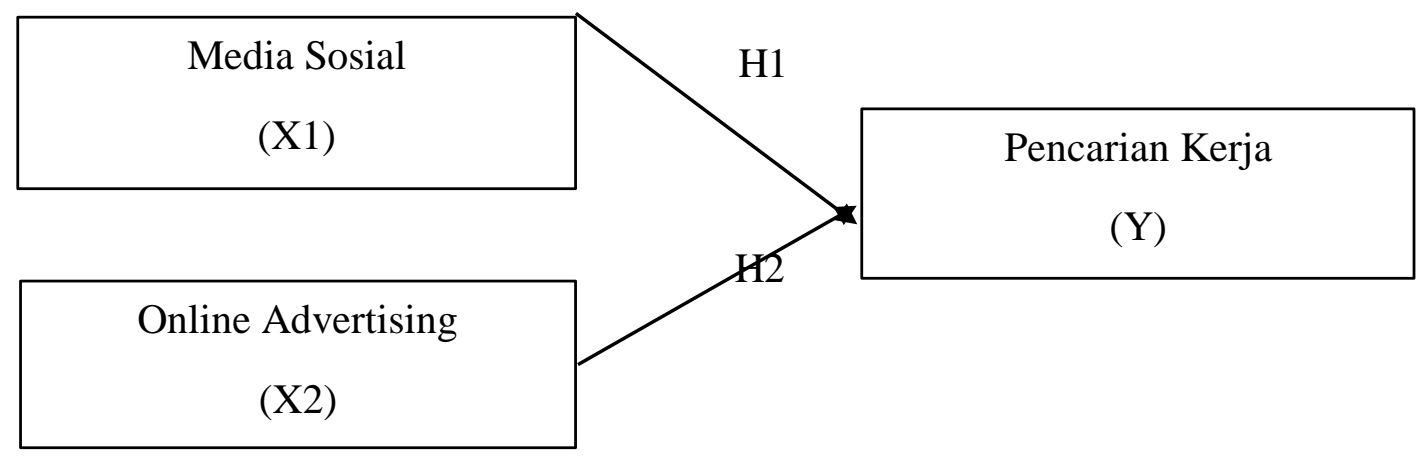

\section{Gambar 1. Model penelitian}

Berdasarkan dari gambar model penelitian yang diatas dapat dirumuskan hipotesis sebagai berikut:

H1: Media Sosial berpengaruh positif dan signifikan terhadap Pencarian Kerja karyawan didaerah Jakarta Barat.

H2: Online Advertising berpengaruh positif dan signifikan terhadap Pencarian Kerja karyawan didaerah Jakarta Barat 


\section{METODELOGI}

Pada penelitian ini, penulis menggunakan metode kuantitatif dengan pengambilan data berdasarkan kuisioner yang akan dibagikan dengan menggunakan skala likert yang dimana akan disebarkan kepada para calon pekerja ataupun karyawan yang sedang bekerja.

Dalam pemilihan sampel dalam penelitian ini adalah menggunakan cara purposive sampling. Yang dimana menurut Sugiyono (2016) menjelaskan bahwa purposive sampling adalah teknik untuk menentukan sampel penelitian dengan beberapa pertimbangan tertentu yang dimana bertujuan agar data yang diperoleh nantinya dapat lebih representatif. Purposive sampling digunakan karena sample dari subjek penelitian harus sesuai dengan kriteria yang telat ditetapkan. Pengambilan sample ini diambil dengan menggunakan google form.

Penelitian ini melakukan pengujian terhadap hipotesis penelitian dengan metode Partial Least Square - Structural Equation Modeling (PLS-SEM) yang dimana dilakukan dengan menggunakan software SmartPLS. Menurut Hair et. al .(2017) menyatakan bahwa dalam pengujian hipotesis didalam suatu penelitian dengan metode analisis PLS-SEM dapat dilakukan dengan cara melihat nilai t-statistik dengan batas minimum nilai adalah 1,96 (tvalue $>1,9, \alpha=5 \%$ ).

Pengukuran variabel-variabel yang digunakan mengacu pada penelitian terdahulu seperti yang ditunjukan pada tabel 1 .

Tabel 1. Pengukuran Variabel

\begin{tabular}{|c|c|c|}
\hline Variabel & Indikator & Sumber \\
\hline Media Sosial & $\begin{array}{l}\text { Saya merasa dengan Media sosial saya dapat menjangkau informasi } \\
\text { lebih luas. } \\
\text { Saya merasa dengan Media Sosial aksebilitas saya dalam mencari } \\
\text { informasi lebih mudah. } \\
\text { Saya merasa penggunan Media sosial sangat mudah dimengerti dan di } \\
\text { pelajari. } \\
\text { Saya merasa informasi yang saya dapatkan di media sosial sama } \\
\text { dengan aslinya. } \\
\text { Saya merasa informasi yang ada di media sosial bisa saja berubah atau } \\
\text { juga menghilang. } \\
\text { Saya menggunakan media sosial dengan waktu yang tidak cepat atau } \\
\text { lama. }\end{array}$ & $\begin{array}{l}\text { Media Sosial Purnama } \\
\qquad(2011: 116)\end{array}$ \\
\hline
\end{tabular}


Saya merasa saat melihat iklan di media sosial saya ingin melihat karena penasaran.

Saya yakin iklan di media sosial dapat mengalihkan perhatian kita.

Saya merasa iklan yang ada di media sosial memiliki daya tarik sendiri.

Online Advertising

Saya merasa iklan harus dibuat agar yang melihat dapat tertarik.

Saya memiliki rasa ingin memiliki saat melihat iklan di media sosial.

Saya merasa ingin mencari informasi lebih lanjut tentang iklan yang

Online Advertising

Djatnika (2007) saya lihat saat membuka media sosial.

Saya akan langsung mencari infomasi tentang iklan yang ada dalam media sosial.

Saya akan langsung melakukan transaksi jika iklan tersebut sesuai dengan apa yang saya cari.

Saya merasa dengan teknologi pada saat ini mencari kerja lebih mudah.

Saya merasa informasi tentang pekerjaan dimedia sosial sangat cepat tersebar.

Saya merasa komunikasi yang diberikan saat bekerja antar pekerja dengan atasan harus memiliki hal positif

Saya yakin komunikasi yang kurang baik didalam pekerjaan akan

Pencarian menyebabkan kesengjangan antar pekerja.

Kerja Saya merasa antara pekerja dan atasan harus memiliki hubungan yang baik.

Menurut Aluri (2019); Holler (2008)

Saya merasa pekerjaan yang saya dapati harus memiliki hubungan antar pekerja yang baik.

Saya merasa mencari pekerjaan di era saat ini harus menggunakan teknologi.

Saya yakin dengan pahamnya teknologi akan memudahkan dalam mencari informasi pekerjaan.

\section{HASIL DAN PEMBAHASAN}

Hasil pengujian validitas pada penelitian ini dapat dinyatakan valid yang dimana ditunjukan pada nilai Average Variance Extracted (AVE). Menurut Ghozali (2014:45) menyebutkan bahwa perhitungan untuk menilai Convergent validity di rekomendasikan menggunakan AVE untuk suatu kriteria. Nilai AVE minimal 0,5 menunjukan ukuran convergent validity yang baik. Artinya dimana variabel laten dapat menjelaskan rata-rata lebih dari setengah varian dari para indikatornya.

Tabel 2. Hasil Pengujian Average Variance Extracted

\begin{tabular}{cc}
\hline Variabel & Average Variance Extracted (AVE) \\
\hline Media sosial & 0.617 \\
\hline Online Advertising & 0.590 \\
\hline Pencarian Kerja & 0.689 \\
\hline
\end{tabular}


Tabel 3. Hasil Pengujian Loading Factor

\begin{tabular}{lccc}
\hline \multicolumn{5}{c}{ Media Sosial $\left(\mathbf{X}_{\mathbf{1}}\right)$} & Online Advertising $\left(\mathbf{X}_{\mathbf{2}}\right)$ & Pencarian Kerja $(\mathbf{Y})$ \\
\hline MS1 & 0.686 & & \\
\hline MS2 & 0.834 & & \\
\hline MS3 & 0.852 & & \\
\hline MS4 & 0.775 & & \\
\hline MS5 & 0.840 & & \\
\hline MS6 & 0.710 & 0.857 & \\
\hline OA1 & 0.870 & \\
\hline OA2 & 0.866 & \\
\hline OA3 & 0.639 & 0.667 \\
\hline OA4 & 0.779 & 0.865 \\
\hline OA5 & 0.772 & 0.835 \\
\hline OA6 & 0.736 & 0.920 \\
\hline OA7 & 0.567 & 0.867 \\
\hline OA8 & & 0.906 \\
\hline PK1 & & 0.778 \\
\hline PK2 & & 0.771 \\
\hline PK3 & & \\
\hline PK4 & & \\
\hline PK5 & & \\
\hline PK6 & & \\
\hline PK7 & & \\
\hline PK8 & & \\
\hline
\end{tabular}

Tabel 4. Hasil Analisis Reliabilitas

\begin{tabular}{ccc}
\hline Variabel & Cronbach's Alpha & Composite Reliability \\
\hline Media sosial & 0.874 & 0.906 \\
\hline Online Advertising & 0.899 & 0.919 \\
\hline Pencarian Kerja & 0.934 & 0.946 \\
\hline
\end{tabular}

Tabel 5. Hasil Analisis Fornell-Larcker

\begin{tabular}{cccc}
\hline Variabel & Media Sosial (X1) & Online Advertising (X2) & $\begin{array}{c}\text { Pencarian Kerja } \\
(\mathbf{Y})\end{array}$ \\
\hline Media Sosial (X1) & 0.786 & & \\
\hline $\begin{array}{c}\text { Online Advertising } \\
\text { (X2) }\end{array}$ & 0.779 & 0.768 & 0.830 \\
\hline Pencarian Kerja (Y) & 0.857 & 0.794 & \\
\hline
\end{tabular}


Tabel 6. Hasil Analisis Cross Loadings

\begin{tabular}{lllc}
\hline & Media Sosial (X1) & Online Advertising (X2) & Pencarian Kerja (Y) \\
\hline MS1 & 0.686 & 0.473 & 0.579 \\
\hline MS2 & 0.834 & 0.541 & 0.721 \\
\hline MS3 & 0.852 & 0.648 & 0.781 \\
\hline MS4 & 0.775 & 0.673 & 0.600 \\
\hline MS5 & 0.840 & 0.743 & 0.749 \\
\hline MS6 & 0.710 & 0.586 & 0.572 \\
\hline OA1 & 0.741 & 0.857 & 0.722 \\
\hline OA2 & 0.744 & 0.870 & 0.747 \\
\hline OA3 & 0.576 & 0.866 & 0.681 \\
\hline OA4 & 0.717 & 0.639 & 0.706 \\
\hline OA5 & 0.519 & 0.779 & 0.547 \\
\hline OA6 & 0.444 & 0.772 & 0.437 \\
\hline OA7 & 0.504 & 0.736 & 0.466 \\
\hline OA8 & 0.322 & 0.567 & 0.337 \\
\hline PK1 & 0.617 & 0.438 & 0.667 \\
\hline PK2 & 0.766 & 0.662 & 0.865 \\
\hline PK3 & 0.721 & 0.714 & 0.835 \\
\hline PK4 & 0.772 & 0.751 & 0.920 \\
\hline PK5 & 0.736 & 0.644 & 0.867 \\
\hline PK6 & 0.806 & 0.754 & 0.906 \\
\hline PK7 & 0.638 & 0.652 & 0.778 \\
\hline PK8 & 0.606 & 0.606 & 0.771 \\
\hline
\end{tabular}

Analisis berikutnya yang dilakukan adalah koefisien determinasi $\left(\mathrm{R}^{2}\right)$ yang berungsi untuk menjunjukan seberapa besar kemampuan variabel media sosial dan online advertising untuk menjelaskan variabel pencarian kerja. Nilai yang diharapkan dari hasil ini yaitu antara 0 sampai dengan 1 . Hasil $\mathrm{R}^{2}$ pada penelitian ini bernilai 0.755 , yang berarti bawah $75,5 \%$ variabel pencarian kerja dapat dijelaskan dengan variabel media sosial dan online advertising. Sisanya sebesar $24,5 \%$ dapat dijelaskan variabel lain yang tidak diteliti dalam penelitian ini. . Pada penelitian ini nilai $\mathrm{Q}^{2}$ juga memiliki nilai sebesar 0.516 dan dapat dikatakan bawah memiliki pengaruh relevance.

Hasil pengujian dari bootstrapping yang ditampilkan pada Tabel 7 dapat menunjukan bahwa pada variabel media sosial memiliki nilai path coefficient sebesar 0.609, dan nilai $T$-statistics yang diperoleh sebesar 4.925 (>1.96) serta nilai dari $p$-value sebesar 0.000 $(<0.05)$. Berarti variabel media sosial $\left(\mathrm{X}_{1}\right)$ memiliki pengaruh yang positif dan signifikan terhadap variabel pencarian kerja (Y). Variabel online advertising memiliki nilai path coefficient sebesar 0.319 , dan nilai $T$-statistics yang diperoleh sebesar $2.597(>1,96)$ serta nilai dari $p$-value sebesar $0.009(<0,05)$. Berarti variabel online advertising $\left(\mathrm{X}_{2}\right)$ memiliki pengaruh positif dan signifikan terhadap variabel pencarian kerja $(\mathrm{Y})$. 
Tabel 7. Hasil Pengujian Hipotesis

\begin{tabular}{ccccc}
\hline Variabel & Path Coefficient & T-Statistics & p-value & Hasil Uji Hipotesis \\
\hline Media Sosial - Pencarian Kerja & 0.609 & 4.925 & 0.000 & Didukung \\
\hline $\begin{array}{c}\text { Online Advertising - Pencarian } \\
\text { Kerja }\end{array}$ & 0.319 & 2.597 & 0.009 & Didukung \\
\hline
\end{tabular}

Pengujian lainnya pada penelitian ini adalah pengujian effect size $\left(f^{2}\right)$ seperti yang ditunjukan pada tabel 7. Hasil dari pengujian tersebut dapat dikatakan bahwa media sosial berpengaruh besar terhadap pencarian kerja karyawan dengan nilai 0.648 , lalu online advertising memberikan pengarub perubahan yang moderat terhadap penarian kerja yaitu sebesar 0.178 .

GOF dapat digunakan untuk membuktikan performa gabungan antara model pengukuran dan dari model struktural secara keseluruhan. Nilai dari Goodness of Fit (GOF) memiliki nilai sebesar 0.691 dan memiliki nilai yang lebih besar dari 0.36 dan dapat digolongkan nilai yang besar.

Tabel 8. Hasil pengujian Effect Size $\left(f^{2}\right)$

\begin{tabular}{cc}
\hline Variabel & Pencarian Kerja \\
\hline Media sosial & 0.648 \\
\hline Online Advertising & 0.178 \\
\hline
\end{tabular}

\section{DISKUSI}

Berdasarkan dari data yang terlah disimpulkan dan dengan kriteria yang telah di tentukan penelitian ini dapat dikatakan baik dan telah memberikan jawaban atas variabelvariabel yang dicari. Menurut Mulyatiningsih (2011:1) menyebutkan bahwa penelitian adalah sebuah cara yang digunakan untuk menemukan jawaban dari pertanyaan-pertanyaan berdasarkan dari pernyataan yang telah di tentukan dan menjadi rumusan masalah dengan menggunakan prosedur. Peneliti dapat memberikan jawaban didalam penelitian ini dan membuktikan kaitan antar variabel juga dapat dibuktikan sesuai dengan angka yang telah ditetapkan. Sudah sesuai dengan apa yang diberikan maka peneli menilai penelitian ini berhasil atau valid karena dapat menjadi acuan untuk penelitian selanjutnya dan juga sudah memberikan informasi apakah media sosial dan online advertising dapat mempengaruhi pencarian kerja. Ternyata dengan hasil yang didapat maka media sosial dan online advertising sangat berpengaruh positif dan signifikan sehingga data menjadi valid dengan meningkatnya pencarian kerja dari pada karyawan yang mencari pekerjaan.

Berdasarkan dari hasil uji hipotesis yang telah dilakukan oleh peneliti bahwa pada variabel media sosial $\left(\mathrm{X}_{1}\right)$ dapat dibuat kesimpulan bahwa $\mathrm{H} 1$ tidak ditolak, media sosial berpengaruh positif dan signifikan terhadap pencarian kerja para karyawan. Artinya, apabila media sosial meningkat maka tingkat pencarian kerja bisa meningkat. Penelitian ini serupa dengan penelitian yang telah dilakukan oleh Mellyana, Prima \& Imran (2018), Ahmad Fauzan (2017), yang dimana mereka menyatakan bahwa media sosial memiliki pengaruh yang positif terhadap pencarian kerja para karyawan. 
Berdasarkan dari hasil uji hipotesis yang telah dilakukan oleh peneliti bahwa pada variabel online advertising $\left(\mathrm{X}_{2}\right)$ dapat dibuat kesimpulan bahwa $\mathrm{H} 2$ tidak ditolak, online advertising berpengaruh positif dan signifikan terhadap pencarian kerja para karyawan . Artinya, apabila online advertising meningkat maka tingkat pencarian kerja bisa meningkat. Penelitian ini serupa dengan peneliian yang telah dilakukan oleh Maryanah, Aldhila, Astrid (2018), Anggita Dwinda (2020), yang dimana mereka telah menyatakan bahwa online advertising memiliki pengaruh yang positif terhadap pencarian kerja para karyawan

\section{KESIMPULAN}

Peneliti dalam penelitian ini ingin meneliti bahwa media sosial dan online advertising memiliki pengaruh positif terhadap pencarian kerja setiap individu dari yang sedang mencari pekerjaan atau yang ingin berpindah ke perusahaan lain. Dari kesimpulan penelitian ini dapat dilihat bahwa responden yang sedang mencari pekerjaan hampir melewati setengah dari total responden. Ini berarti dapat disimpulkan bahwa pada era modern saat ini media sosial dan online advertising dapat membantu setiap individu yang ingin mencari pekerjaan. Bisa dilihat dari hasil akhir bahwa H1 Media sosial berpengaruh positif dan memiliki nilai yang melebihi syarat dan juga $\mathrm{H} 2$ Online Advertising berpengaruh positif dan memiliki nilai yang melebihi syarat, dan dapat dibuktikan sebagai berikut:

1.Media Sosial berpengaruh positif terhadap Pencarian kerja karyawan di daerah Jakarta Barat. Hal ini dapat dibuktikan dengan nilai path coefficient sebesar 0.609. Pengaruh positif juga dapat ditunjukan dengan nilai $\mathrm{T}$-statistics sebesar 4.925, yang nilainya sudah melebihi dari syarat yang telah ditentukan yaitu 1,96. Dan p values menghasilkan nilai 0.000 yang dimana tidak melebihi dari syarat yaitu 0.05 .

2.Online Advertising berpengaruh positif terhadap Pencarian kerja karyawan di daerah Jakarta Barat. Hal ini dapat dibuktikan dengan nilai path coefficient sebesar 0.319. Pengaruh positif juga dapat ditunjukan dengan nilai T-Statistics sebesar 2.597, yang nilainya sudah melebihi dari syarat yang telah ditentukan yaitu 1,96. Dan $\mathrm{p}$ values menghasilkan nilai 0.009 yang dimana tidak melebihi dari syarat yaitu 0.05 .

Jika disimpulkan berdasarkan poin dari hasil penelitian ini dapat dikatakan sebagai berikut:

1.Bahwa peneliti telah meneliti ke 54 responden secara acak didaerah jakarta barat dan mendapatkan respons yang positif.

2.Peneliti telah mendapatkan jawaban bahwa media sosial memiliki pengaruh positif dan signifikan terhadap pencarian kerja.

3.Peneliti telah mendapatkan jawaban bahwa online advertising memiliki pengaruh positif dan signifikan terhadap pencarian kerja.

4.Peneliti memiliki pandangan dan jawaban dari penelitian ini bahwa media sosial dan online advertising pada saat ini tidak hanya untuk menjual produk atau jasa tetapi juga bisa menjadi saran mencari pekerjaan atau mencari pekerja.

Saran bagi para karyawan yang mencari pekerjaan menggunakan media sosial dan menemukan informasi dari online advertising, peneliti memberikan saran bahwa dalam pencarian informasi didalam media sosial atau menerima online advertising yang berisikan informasi tentang pekerjaan, harus diteliti atau di check kembali karena akan maraknya penipuan dengan berbasis internet. Dengan begitu para karyawan dapat bekerja tanpa 
kekhawatiran dengan hal seperti itu. Lalu peneliti juga menyarankan bahwa pada era modern seperti ini menggunakan media sosial dan mendapatkan iklan online merupakan hal yang sudah biasa dan akan membantu mempermudah pekerjaan kita nanti.

Saran bagi penelitian selanjutnya Peneliti berharap suatu saat akan ada peneliti yang meneliti variabel serupa mungkin dengan variabel yang berbeda atau berkaitan atau juga dengan variabel yang sama kemudia ditambahkan variabelnya. Peneliti berharap ini bisa menjadi acuan dasar dalam penelitian selanjutnya dan berharap juga agar variabel ditambahkan.

\section{DAFTAR PUSTAKA}

Ahmad Fauzan (2017), dalam artikel: "Perilaku di Media Sosial, Pengaruhi Karir kamu!," 28 april 2021

Aluri, A. (2009). "To investigate the usage of social networking sites as a career enhancement tool among Generation Y: An empirical research.”. Journal School of Hotel and Restaurant Administratrion.

Anggita Dwinda (2020), dalam artikel: "Manfaat Pasang Iklan Lowongan Kerja di JobPortal." 28 april 2021

Alvionita \& Mei Ie. (2021), "PENGARUH KONTEKS TEKNOLOGI, KONTEKS ORGANISASI DAN KONTEKS LINGKUNGAN TERHADAP ADOPSI MEDIA SOSIAL BAGI UMKM". Jurnal Muara Ilmu Ekonomi dan Bisnis Vol.5, No. 1, April 2021 : hlm 214-224. DOI : $\quad$ https://doi.org/10.24912/jmieb.v5i1.11185

Chaffey, D. (2018), Digital Marketing, Strategy, Implementation, and practice.ISBN-13:9781292077611

Djatnika, Tjetjep. 2007. Komunikasi Pemasaran. Bandung: PT Remaja Rosdakarya.

Ghozali, Imam. 2014. Structural Equation Modeling, Metode Alternatif dengan Partial Least Square (PLS). Edisi 4. Semarang : Badan Penerbit Universitas Diponegoro.

Kotler, Phillip dan Garry Amstrong. (1997). Dasar-dasar Pemasaran. Alih Bahasa Alexander Sindoro. Jilid dua. Jakarta: Prenhalindo

Kotler,Philip \& Keller K.L.(2009). Manajemen Pemasaran edisi 13 jilid 2.Jakarta:Erlangga

Larson, K., \& Watson, R. (2011). "The value of social media: toward measuring social media strategies". Thirty second international conference on information system, Shanghai, 2011.

Maryanah Safitri, Aldhila Novianti, Astrid Noviriandini (2018), 'SISTEM INFORMASI LOWONGAN KERJA BERBASIS WEB”, Jurnal PILAR Nusa Mandiri Vol. 14, No. 1 Maret 2018.

Mellyna Eka Yan Fitri, Prima Yulianti, Imran Agus (2018). "PENGGUNAAN MEDIA SOSIALDI LINGKUNGAN KERJA DI PERGURUAN TINGGI XYZ”, Vol IV no. 1

Plummer, M., Hiltz, S. R., \& Llotnick, L. (2011). "Predicting intentions to apply forjobs using social networking sites: An exploratory study. "HICSS 11,Proceedings of the 2011 $44^{\text {th }}$ Hawaii intern

Purnama, Hadi (2011). Media Sosial Di Era Pemasaran 3.0 Corporate And Markerting Communication . Jakarta: Pusat Studi Komunikasi dan Bisnis Pasca sarjana Universitas Mercu Buana .Pp107-124

Suhartono Chandra \& Richard Andrew (2018). "PERAN MEDIA SOSIAL DALAM STRATEGI KOMUNIKASI PEMASARAN DI SEBUAH PERGURUAN TINGGI 
SWASTA DI JAKARTA BARAT". Jurnal Muara Ilmu Ekonomi dan Bisnis Vol. 2, No. 2, Oktober 2018: hlm 535-542.

Sugiyono. (2016). Metode penelitian kuantitatif, kualitatif, dan kombinasi (Mixed Methods).Alfabeta:

Bandung.

DOI:http://jom.untidar.ac.id/index.php/market/article/view/639 